\title{
Wear Behaviour of Electroless heat Treated Ni-P Coatings as Alternative to Electroplated hard Chromium Deposits
}

\author{
Felipe Samuel Goettems ${ }^{a *}$, Jane Zoppas Ferreira ${ }^{a}$ \\ ${ }^{a}$ Programa de Pós-Graduação em Engenharia de Minas, Metalúrgica e de Materiais - PPGEM, \\ Universidade Federal do Rio Grande do Sul - UFRGS, Av. Bento Gonçalves, 9500, B. Agronomia, \\ 91501-970, Porto Alegre, RS, Brazil
}

Received: April 04, 2017; Revised: June 12, 2017; Accepted: July 03, 2017

\begin{abstract}
In this present study was evaluated the influence of heat treatment on the wear resistance of electroless high phosphorus nickel coating (9-10\% $\mathrm{P}$ wt.). In addition, both untreated and treated Ni-P deposits were then compared to electroplated hard chromium coatings in terms of wear behaviour. Three different heat treatment conditions were performed at temperatures of $320^{\circ} \mathrm{C}, 400^{\circ} \mathrm{C}$ and $500^{\circ} \mathrm{C}$ under different holding times. The selection of the heat treatment conditions was chosen considering the results obtained by a differential scanning calorimetry (DSC) analysis. The wear behaviour of the $\mathrm{Ni}$-P samples was investigated through a non-lubricated "ball on plate" test carried out against an $\mathrm{Al}_{2} \mathrm{O}_{3}$ counter-face. After an analysis of the friction coefficient, microstructure of the worn surface, width and chemical composition of the wear track, was possible to conclude that the heat treatment affect positively the wear resistance of Ni-P coatings. Treatment conditions of $320^{\circ} \mathrm{C}$ with 9 hours holding time and $400^{\circ} \mathrm{C}$ with 1 hour holding time showed the best results due to a structural change from amorphous supersatured solid solution of phosphorus in nickel to a crystalline structure of nickel crystallites and nickel phosphides $\left(\mathrm{Ni}_{3} \mathrm{P}\right)$ occurred between $320^{\circ} \mathrm{C}$ and $360^{\circ} \mathrm{C}$ that was verified after $\mathrm{x}$-ray diffraction analysis. Moreover, Ni-P heat treated coatings showed better results when compared to electroplated hard chromium deposits, hence acting as a natural alternative for chromed coatings.
\end{abstract}

Keywords: Metallic coatings, Wear, Nickel electroless, Heat treatment, Hard chromium

\section{Introduction}

Electrodeposited hard chromium coatings are widely used in several areas where wear resistance must be a fundamental property. Only a few microns' thick layer deposited on a varied range of substrates is capable to reduce considerably their friction coefficient as well as their mass loss during application of a load under dynamic movement. This special ability has always made hard chromium a vital allied of industry, allowing the use of soft and inexpensive base materials even when exposed to severe wear conditions.

However, over the last decade the efforts to replace hard chromium coatings has increased especially due to environmental concerns related to chemical products involved in the deposition process. The expensive waste disposal that is required after electrodeposition and the well-known health problems originated by the carcinogenic chromate have influenced the industrial sector to develop "cleaner" plating baths. Nowadays, several environmental friendly alternatives have been studied in order to substitute hard chromium without loss of the most important properties for a specific case.

Following this line of reasoning, one of the most studied coating process in the past 10 years is the electroless nickel

* e-mail: felipegoettems@yahoo.com.br plating. These extensive studies are primarily due to their high wear resistance and effective corrosion protection. The most common electroless nickel deposition is formed through a metallic alloy composed by nickel and phosphorus, but the possibilities of combining different elements are quite large ${ }^{1}$.

One of the greatest advantages of the electroless method in comparison of all types of electrodeposited process is related to absence of electricity resulting in a homogeneous deposit covering all the substrate surface at the same level so that eliminating the electrostatic effect that has been verified in coated parts containing sharp edges. In addition, during the hard chromium electrodeposition an intensive reaction involving the release of hydrogen is often observed leading to formation of a micro crack network along the coating, consequently reducing important properties such as corrosion resistance ${ }^{2-6}$.

The microstructure of the Ni-P deposit is quite dependent of the phosphorus content and their properties change drastically as well. Several studies have reported that increasing the phosphorus amount above values of $9 \% \mathrm{P}$ wt., the tendency of an amorphous structure formation is increased, leading to a higher corrosion resistance ${ }^{7-12}$. Studies have observed that with appropriate heat treatment (transformation occurred around $340^{\circ} \mathrm{C}$ ) the metastable amorphous structure could be transformed into an equilibrium fully crystalline structure 
composed by $\mathrm{Ni}_{3} \mathrm{P}$ and nickel crystallites, so that enhancing hardness and corrosion resistance ${ }^{13-21}$. TAHERI ${ }^{22}$ has also verified that the higher the content of phosphorus, the greater the formation of $\mathrm{Ni}_{3} \mathrm{P}$ precipitates.

The most of the studies have found that the ideal heat treatment condition in terms of hardness and wear is achieved when heated at $400^{\circ} \mathrm{C}$ during 1 hour holding time ${ }^{10,14,16,18,22}$. This condition is proved to reach the structural stability. Some authors have observed the formation of $\mathrm{NiO}$ phase when the temperature overtake $450^{\circ} \mathrm{C}$, reducing the wear resistance of the Ni-P coatings ${ }^{15,23}$. It is consensus that relative high holding times ( 1 hour for instance) at temperatures above $450^{\circ} \mathrm{C}$ makes a coarsening effect of nickel phosphides and nickel crystallites leading to an increasing mass loss during wear tests ${ }^{18,24-26}$. In this same temperature a study has found that when the coating is applied to an aluminum based alloy substrate, reactions between the deposit and base material lies just at the interface region, producing intermetallic compounds leading to a reduction in the wear resistance?. Investigations have reported that heat treatments carrying out at temperatures below to $300^{\circ} \mathrm{C}$ cannot provide benefits in terms of wear probably due to do not reach the structural transformation temperature ${ }^{18,20,25}$.

In this present work, an attempt to improve the wear resistance of autocatalytic Ni-P coatings through adequate heat treatment was performed. In addition, it is expected that heat treated Ni-P coatings could present higher wear behaviour than hard chromium deposits. Nickel-phosphorus and hard chromium coatings which were deposited on a martensitic stainless steel SAE HNV3 were conducted to an unlubricated "ball on plate" wear test, and the results were then compared to their microstructural changes which were evaluated by different analytic methods.

\section{Materials and Methods}

\subsection{Coating preparation}

Ni-P coating were deposited on a martensitic stainlesssteel SAE HNV3 substrate. Prior to the deposition, all samples were degreased by an immersion in a $\mathrm{KOH}$ alkaline solution for 10 minutes. After that, in order to improve the adhesion, the samples were superficially activated using $\mathrm{H}_{2} \mathrm{SO}_{4} 5 \%$ for 2 minutes and then were conducted to the acid plating solution. A commercial Ni-P electroless plating bath (NICHEM 2100 PLUS - ATOTECH) with sodium hypophosphite as reducing agent was used to obtain the coatings. The $\mathrm{pH}$ of the plating solution was kept at 4.8 and the temperature deposition was adjusted to $88^{\circ} \mathrm{C}$. The $\mathrm{Ni}^{2+}$ solution concentration was kept at $5.6 \mathrm{~g} / \mathrm{L}$ and the loading ratio was fixed at $1.25 \mathrm{dm}^{2} / \mathrm{L}$. All of these parameters were adjusted to produce a high phosphorus electroless coating. The plating time was 25 minutes.
Heat treatments of the as-deposited Ni-P coatings on the stainless-steel substrate were carried out in an electric furnace. The coatings were isothermally heat-treated for 1 hour at two different temperatures, i.e. $400^{\circ} \mathrm{C}$ and $500^{\circ} \mathrm{C}$. The heat treatment temperature of $320^{\circ} \mathrm{C}$ was also used, but with a holding time of 9 hours. The reason is that the crystallization temperature range lies between $320^{\circ} \mathrm{C}$ and $360^{\circ} \mathrm{C}$, so that only 1 hour could be insufficient to complete the phase transformation. At the end of the heat treatments, the specimens were cooled down at the air.

Hard chromium coatings were obtained purchasing automotive parts (diesel engine exhaust valves) from a current supplier of these parts to the automotive industry. The exhaust valve is produced with the same substrate of those used to autocatalytic Ni-P deposit (stainless steel SAE HNV3).

\subsection{Coating characterization}

Phosphorus content of the Ni-P samples was determined by energy dispersive X-ray spectroscopy (EDS) using a scanning electron microscope (SEM). The thickness of the Ni-P and hard chromium coatings was evaluated by an optical microscope (MO) through the cross-sectioned samples. The cut-off length was fixed at $5 \times 0.8 \mathrm{~mm}$. Phosphorus content and coating thickness of the as-deposited Ni-P and hard chromium as well as the heat-treated samples data are exposed in Table 1.

Table 1. Electroless Ni-P and hard chromium coatings characteristics.

\begin{tabular}{ccc}
\hline Sample & $\begin{array}{c}\text { Phosphorus } \\
\text { Content }\end{array}$ & Coating Thickness \\
\hline Hard chromium & - & $5.0 \mu \mathrm{m} \pm 0.1 \mu \mathrm{m}$ \\
EN as-deposited & $9.4 \%$ & $5.7 \mu \mathrm{m} \pm 0.3 \mu \mathrm{m}$ \\
EN 320 - 9 & $9.1 \%$ & $6.2 \mu \mathrm{m} \pm 0.2 \mu \mathrm{m}$ \\
EN 400 - 1 & $10.1 \%$ & $5.2 \mu \mathrm{m} \pm 0.4 \mu \mathrm{m}$ \\
EN 500 - 1 & $9.9 \%$ & $6.4 \mu \mathrm{m} \pm 0.3 \mu \mathrm{m}$ \\
\hline
\end{tabular}

In the case of the Ni-P samples, surface roughness average (Ra) was measured prior and after the deposition process using a portable surface roughness tester Digimess 200.400.

Differential scanning calorimetry (DSC) experiment was carried out using a heat flux DSC Netzsch Pegasus $404 \mathrm{~F} 1$ equipment in a range of temperature between $20^{\circ} \mathrm{C}$ to $500^{\circ} \mathrm{C}$. The heating rate used was limited to $10 \mathrm{~K} / \mathrm{s}$ and the atmosphere of the test was composed by $\mathrm{N}_{2} / \mathrm{O}_{2}$. The asdeposited Ni-P coating was mechanically removed so that was conducted to DSC tester in the powder form.

$\mathrm{X}$-Ray diffraction (XRD) was used to investigate the structural evolution of Ni-P coatings (i.e. as-deposited and heat-treated). The measurements were performed on a Philips $\mathrm{X}$ 'Pert diffractometer using $\mathrm{Cu} \mathrm{K} \alpha$ radiation. The treatment 
of the results obtained by the XRD analysis were performed using the X'Pert High Score Plus crystallographic software.

Wear tests were carried out on an unlubricated ball-onplate system using a CETR sliding tester. The coefficient of friction $(\mathrm{COF})$ was real time monitored with a computer interfaced data acquisition system. As a counter face, an $\mathrm{Al}_{2} \mathrm{O}_{3}$ ball (4.72 $\mathrm{mm}$ in diameter) was forced against the surface coating and encouraged to slide on it keeping a constant load of $6 \mathrm{~N}$. The linear displacement of the ball on the coating surface was kept in $2 \mathrm{~mm}$ and the duration of the test was fixed in 40 minutes. Once the tests were done, the coatings were conducted to an optical microscope in order to evaluate the width of the worn track.

\section{Results and Discussion}

\subsection{Physical and microstructural evaluation}

Whereas that the literature has found some potential conditions of heat treatment of electroless Ni-P in terms of wear resistance, the relationship between temperature and time experimented in this paper was based through those has been done so far. Moreover, a differential scanning calorimetry (DSC) test was performed in Ni-P as-deposited condition in order to verify the range of temperature when structural modification occurs for this specific alloy. The results obtained in this test are exposed in Figure 1.

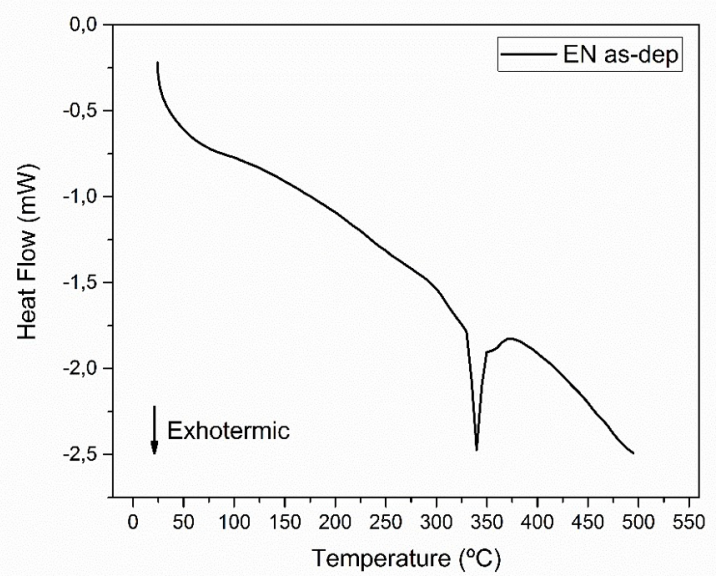

Figure 1. DSC test in Ni-P as-deposited condition.

As can be observed from Figure 1, there is an exothermic peak that takes place in the range of temperatures from $320^{\circ} \mathrm{C}$ to $360^{\circ} \mathrm{C}$. This peak is massive referenced by several authors ${ }^{18,22,23}$ as being the transformation of amorphous state to a complete crystalline structure of the electroless Ni-P alloys with high phosphorus content.

Figure 2 shows the structural evolution of electroless Ni-P coatings as a function of heat treatment. As has already been shown in several studies ${ }^{17,22,23}$, the structure of as- deposited Ni-P coating is amorphous, consisting basically of a supersaturated solid solution of phosphorus in nickel matrix. Only one broad diffraction peak was found around $2 \theta=\sim 45^{\circ}$ and is related as being the FCC nickel (111). When heat treatments were performed, substantially differences can be noted in the diffraction pattern. After annealing either at $320^{\circ} \mathrm{C}$, or at $400^{\circ} \mathrm{C}$ and at $500^{\circ} \mathrm{C}$ the same behaviour was observed. Firstly, the matrix is no longer the same of the as-deposited Ni-P condition. Instead of the presence of a FCC nickel broad diffraction peak, there was a combination of two phases, namely FCC nickel (i.e. Ni (111) and (220)) and $\mathrm{BCT}$ nickel phosphide $\left(\mathrm{Ni}_{3} \mathrm{P}\right)$. It is confirmed by the formation of sharp diffraction peaks at different $2 \theta$ angles that can be seen in the diffraction patterns leading to a formation of a crystalline structure. Such characteristic was already expected and is widely reported by the literature. As reported by APACHITEY et al. ${ }^{18}$, a segregation process of phosphorus in the grain boundaries and triple junctions of Ni-P grains occurs with increasing temperature, leading to a formation of $\mathrm{P}$-rich zones. Precipitation of $\mathrm{Ni}_{3} \mathrm{P}$ phase occurs when P-rich zones exceed a certain phosphorus limit, around eutectic concentration (i.e. $11 \mathrm{wt} \% \mathrm{P}$ ). There is also evidence that $\mathrm{Ni}_{3} \mathrm{P}$ precipitates are preferentially located at the grain boundaries and triple junctions.

\subsection{Tribological evaluation}

Surface roughness is quite important when friction and wear behaviour are evaluated in metallic coatings. Usually, the higher the value of surface roughness, the higher is the friction coefficient and the reason is related to the movement obstruction when two bodies are under mutual contact ${ }^{27-28}$. In Figure 3 are exposed the results obtained after measurement of surface roughness. It can be noted that in comparison to substrate there was a reduction verified for Ni-P coatings. It can be explained by the fact that electroless coatings are deposited homogeneously on the material base acting as a sealant in areas with elevated average roughness. This fact has already been cited by LEE et al. ${ }^{29}$ and VITRY et al. ${ }^{30}$. For the hard chromium coating, the effect was opposite. Most of this result can be related to electrostatic effect caused by the electroplated process, where regions with sharp edges are covered at different levels and consequently improving the average surface roughness.

In Figure 4 are exposed the results obtained after the unlubricated "ball on plate" wear test. These results are represented through the variation of the friction coefficient (COF) along the time using an alumina ball as the counter-face.

Higher COF values generally represent unfavorable results in terms of wear resistance. The friction coefficient for heat treated $\mathrm{Ni}-\mathrm{P}$ deposits presented better results than those obtained by the Ni-P coating in as-deposited condition. In addition, all of the Ni-P heat treated coatings showed better 

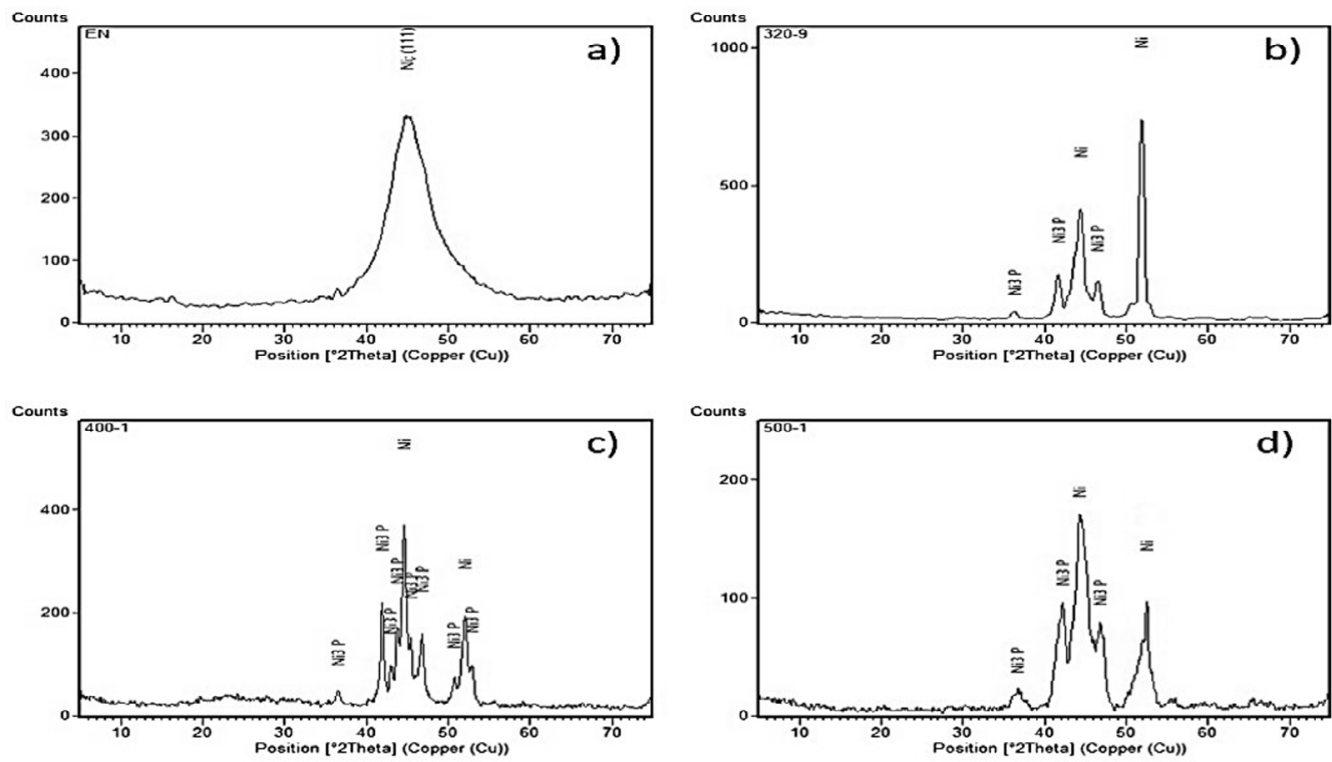

Figure 2. XRD patterns for electroless Ni-P coatings at different heat treatment conditions: a) EN as-deposited; b) EN 320-9; c) EN 400-1; d) EN 500-1.

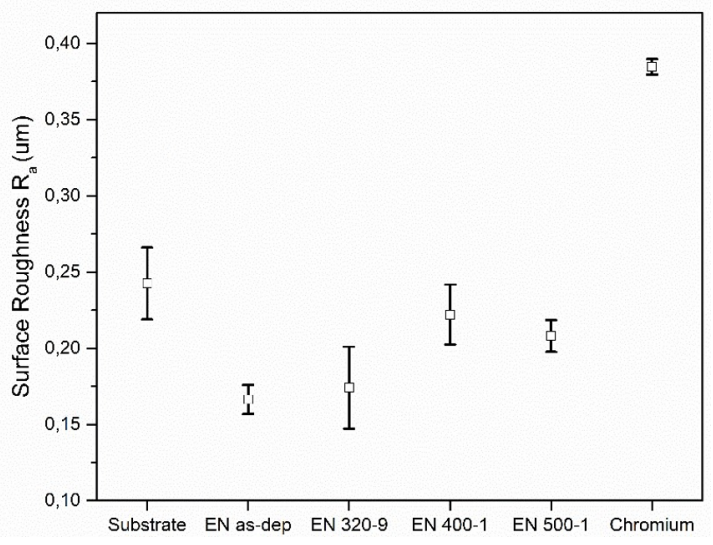

Figure 3. Average surface roughness for Ni-P and hard chromium coatings.

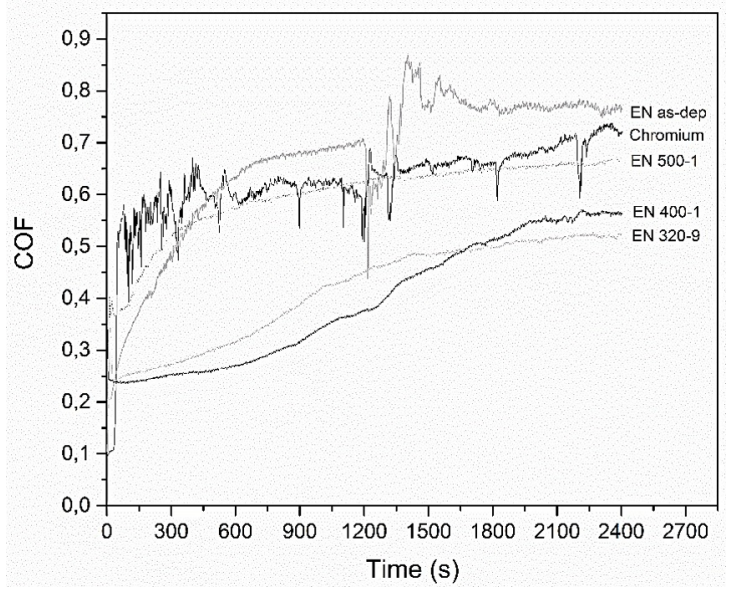

Figure 4. COF curves for all the specimens. results in comparison with hard chromium specimen, with exception to as-deposited condition.

Heat treatments conducted at $320^{\circ}$ and $400^{\circ} \mathrm{C}$ showed the lowest COF after "ball-on-plate" test, indicating these temperatures as being appropriate when wear resistance is mandatory. At the beginning of the test, the COF values for these two heat treatment temperatures were found to be 0.2 , reaching the same value that several studies ${ }^{14,16,28}$ with respect to electroless nickel-phosphorus have already found. At the end of the test, COF values were found to be 0.5 and 0.55 , respectively, after a gradual increase throughout the time. Even $500^{\circ} \mathrm{C}$ condition improved the $\mathrm{COF}$ value in comparison with Ni-P as deposited, reaching values of 0.65 , and differing by their sharply increase.

The Ni-P as-deposited condition showed final COF values around 0.8 , probably reaching the substrate. It can be deducted by analyzing the COF curve after 1100 seconds from the beginning of the test, when an abrupt decrease can be observed suggesting the rupture of the deposit. According to PALANIAPPA et al. ${ }^{24}$, the decreasing of COF values in electroless nickel-phosphorus alloys after heat treatment is explained by the formation of a thin layer of nickel oxide (NiO) at the coating surface that acts as natural lubricant. According to MA et al. ${ }^{20}$, nickel oxide is formed due to relative high temperature experienced during the heat treatment and its formation occurs only in uncontrolled atmosphere furnace.

Hard chromium coating assumed values of COF around 0.6 at the end of the wear test. Moreover, it can be noted a considerable oscillation when the $\mathrm{COF}$ reached 0.5 indicating that at this moment a third body intruded into coating and counter-face system, probably due to the rupture of the deposit. The higher value of COF found for hard chromium 
coating in comparison with the Ni-P heat treated conditions can also be attributed to their higher surface roughness, once the wear test was carried out in dry condition so that favoring the creation of high local pressure areas. Similar behaviour has found by BALAMURUGAN et al. ${ }^{4}$ when compared hard chromium with plasma sprayed WC coating.

In order to understand the wear mechanisms of the coatings after the "ball-on-plate" test, wear track patterns were evaluated using optical and scanning microscopy techniques. The width of the wear track was also measured in order to compare among the different specimens assuming that the wider the worn track, the higher the wear rate. This conclusion is easy to understand by the fact that, keeping constant all the parameters in the "ball-on-plate" test, the indentation of the ball onto the sample will be deeper and wider for less wear resistant specimens.

Analyzing the worn surface for the Ni-P as-deposited condition, a huge amount of abrasive scratches can be seen (Figures 5a) indicating the presence of abrasive wear mechanism. It is also possible to observe the presence of adhered material at the counter-face (Figure 5b), leading to a conclusion that adhesive wear mechanism is also present. This result was already expected when two metallic materials are placed in contact ${ }^{27}$. The width of the worn track was found as $463 \mu \mathrm{m}$.
The improvement in the wear behaviour of the heat treatments that has been verified in COF curves is also present when analyzing the wear track patterns. For the $320^{\circ} \mathrm{C}$ Ni-P heat treatment condition, a sharply reduction in the number of scratches (Figure 6a) and in the amount of adhered material (Figure $6 \mathrm{~b}$ ) were verified in comparison of $\mathrm{Ni}-\mathrm{P}$ as-deposited. In addition, the width of the worn track was quite less than Ni-P as-deposited condition, reaching values of $168 \mu \mathrm{m}$.

Similar characteristic was observed for $400^{\circ} \mathrm{C}$ heat treatment condition. A huge reduction in the scratches (Figure 7a) and adhered material (Figure 7b), and in the width of the worn track $(164 \mu \mathrm{m})$ was detected. These results are directly correlated to $\mathrm{COF}$ values obtained in the "ball on plate" test, when $320^{\circ} \mathrm{C}$ and $400^{\circ} \mathrm{C}$ conditions showed similar COF results.

The width of the worn track for $500^{\circ} \mathrm{C}$ condition showed values around to $204 \mu \mathrm{m}$ and represents a slightly decrease in terms of wear behaviour in comparison to other two heat treatment conditions. Moreover, the amount of scratches (Figure 8a) is superior when compared to $320^{\circ} \mathrm{C}$ and $400^{\circ} \mathrm{C}$ conditions and reflects the values of $\mathrm{COF}$ that have been found in the wear test.

When the wear behaviour is analyzed for hard chromium specimen, it is noted a similar characteristic to Ni-P as-

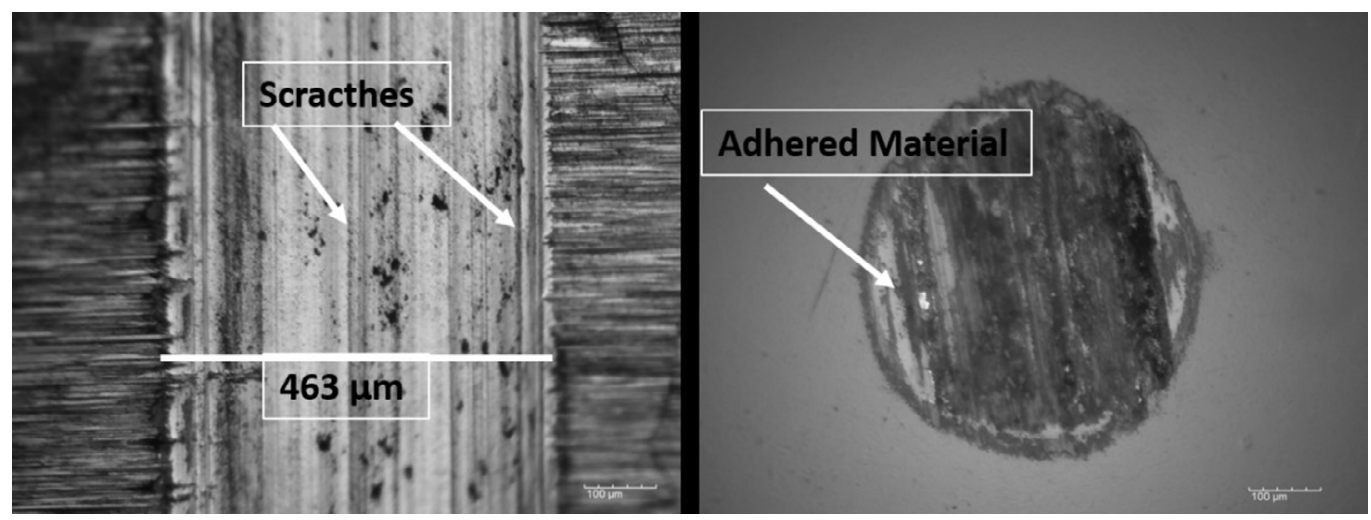

Figure 5. Worn track for the EN as-deposited condition: a) wear pattern; b) counter-face aspect.

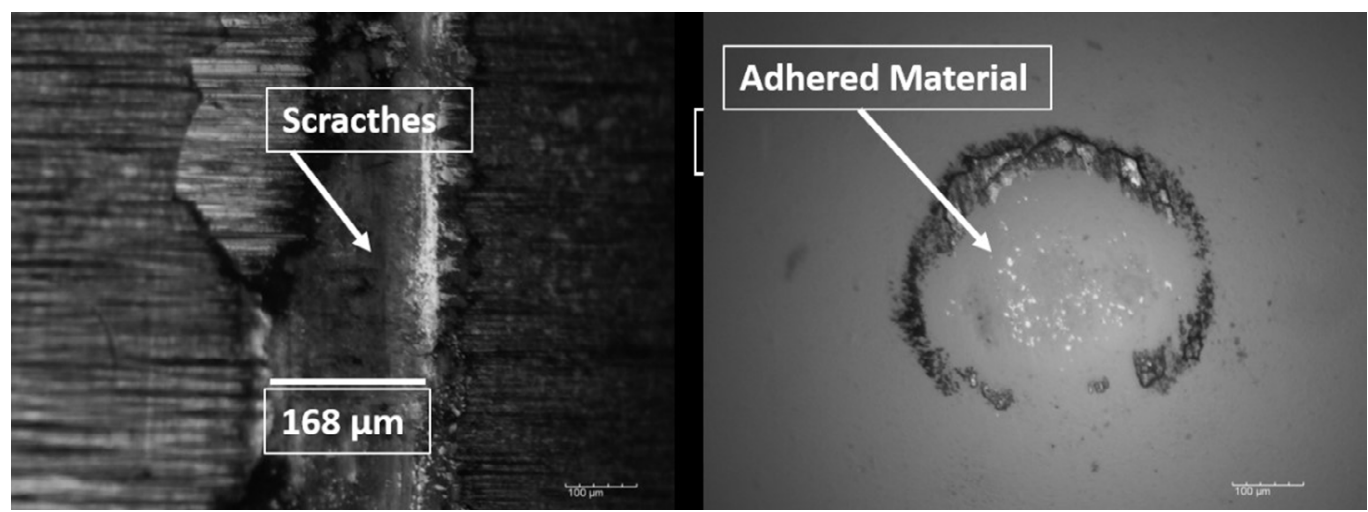

Figure 6. Worn track for the EN 320-9 condition: a) wear pattern; b) counter-face aspect. 


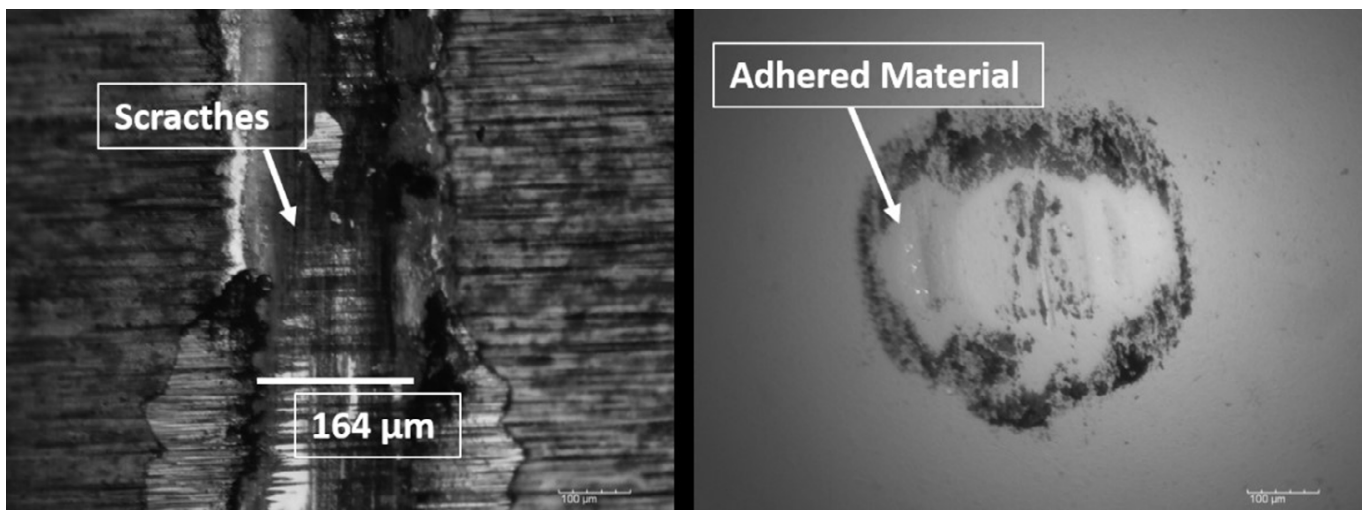

Figure 7. Worn track for the Ni-P 400-1 condition: a) wear pattern; b) counter-face aspect.

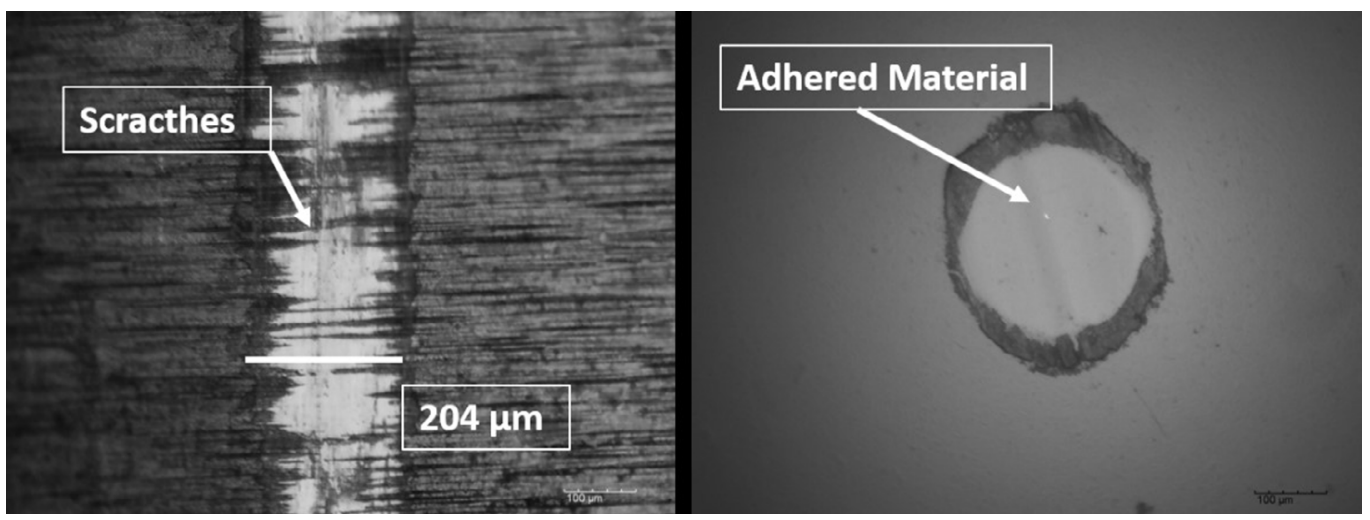

Figure 8. Worn track for the Ni-P 500-1 condition: a) wear pattern; b) counter-face aspect.

deposited condition. Wear scratches are clearly evidenced (Figure 9a) as well as the adhered material at the counter-face (Figure 9b). In addition, the width of the worn track is much higher when compared to Ni-P heat treated samples $(404 \mu \mathrm{m})$.

A direct relationship among friction coefficient, amount of wear scratches and width of the worn track was clearly observed in this study. The higher the COF value, the higher the amount of abrasive scratches and wider is the worn track. This trend was already expected for Ni-P and hard chromium coatings and it is useful to evaluate their wear behaviour. Several authors have already noticed better wear performance in Ni-P samples after heat treatment ${ }^{8}, 18,24$, but these results when compared to hard chromium were unexpected due to well-known high hardness. Hence, not taking into account the lowest values of surface roughness for Ni-P coatings, it can be assumed that heat treated Ni-P deposits have equal or even higher mechanical properties than hard chromium.

Analyzing the width of worn track, Ni-P heat treated coatings showed higher wear resistance when compared to hard chromium and untreated Ni-P deposits. It is consensus that the transformation of metastable phase composed by phosphorus supersatured solid solution in nickel matrix in $\mathrm{Ni}_{3} \mathrm{P}$ precipitates and $\mathrm{Ni}$ crystallites is the responsible for the improvement in hardness and consequently in wear behaviour ${ }^{18,20,25,31}$. The reason for the $500^{\circ} \mathrm{C}$ and 1 hour holding time condition showed a slightly reduction in the wear behaviour in comparison to another heat treatment conditions can be explained by the fact that the temperature of the heat treatment is superior, providing a growth in the $\mathrm{Ni}_{3} \mathrm{P}$ precipitates and $\mathrm{Ni}$ crystallites ${ }^{18,24}$, consequently reducing the mechanical properties of the coating. Even so, this result is better than Ni-P as-deposited condition. Has also been cited that when holding Ni-P alloys in temperatures above $450^{\circ} \mathrm{C}$ can occur a diffusion of chemical elements from substrate in direction to the coating leading to a formation of intermetallic phases $^{9}$ so that decreasing the mechanical properties.

In relation to the wear mechanisms it is clear that abrasive is the main component acting in the system, although adhesive wear is also present. For the heat treated Ni-P samples, this fact can be related to the presence of the hard particles of $\mathrm{Ni}_{3} \mathrm{P}$ which acts as third body at the contact surface during the wear test ${ }^{32}$. For the Ni-P as-deposited condition and hard chromium specimens, this fact can be attributed to the rupture of the film verified in the COF curves during the "ball on plate" test. In addition, in all samples the difference in terms of hardness between the counter-face (alumina) and the deposit is high, favoring an abrasive mechanism ${ }^{27}$. 


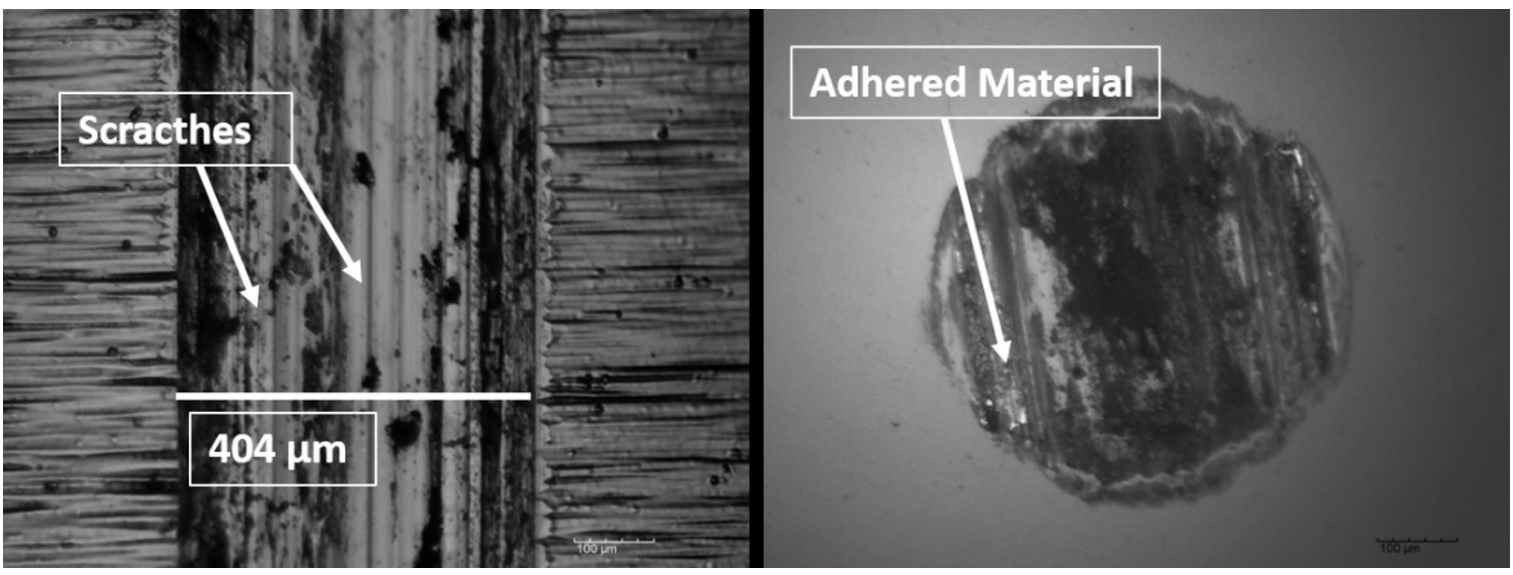

Figure 9. Worn track for the hard chromium specimen: a) wear pattern; b) counter-face aspect.
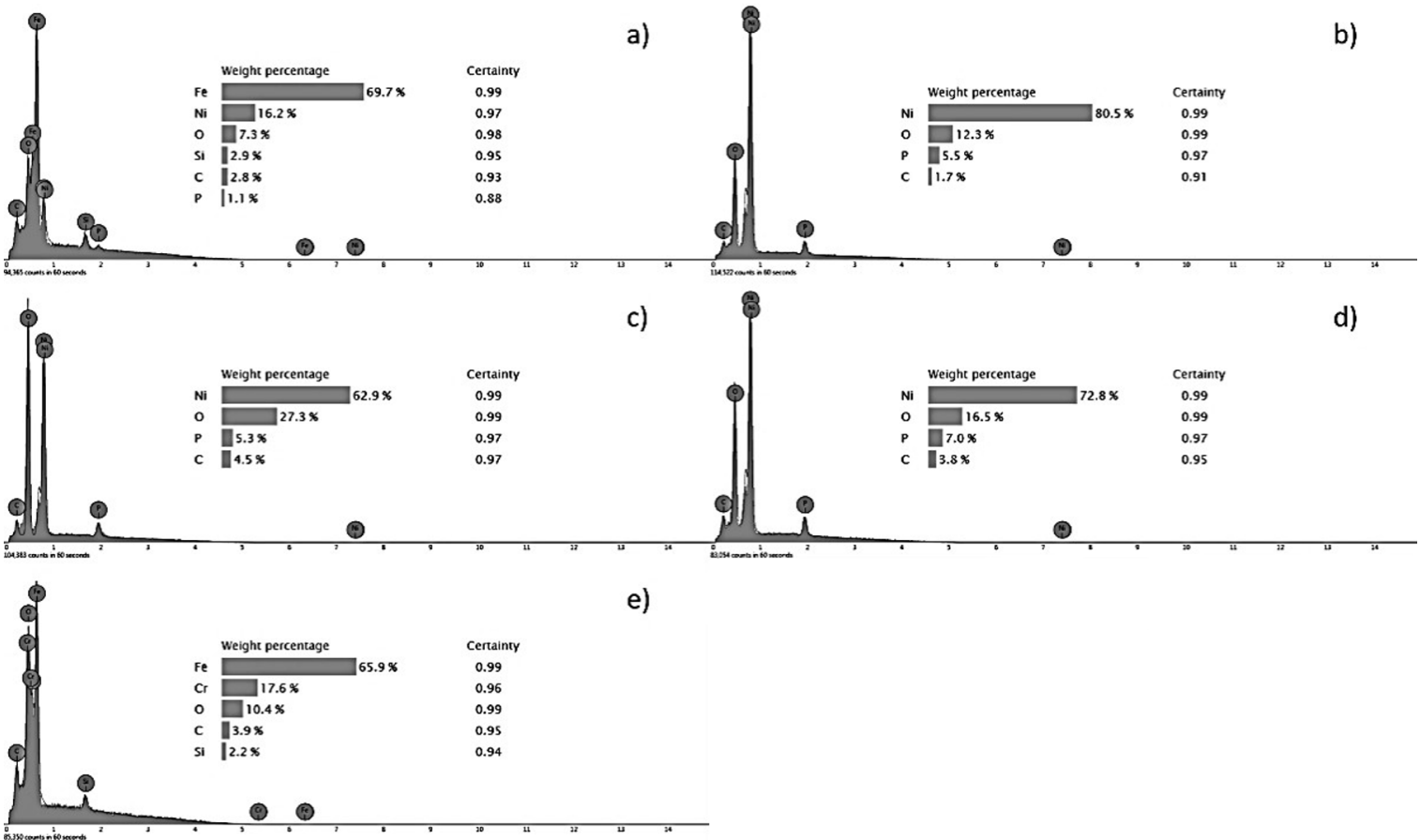

Figure 10. EDS analysis of the wear track: a) EN as-deposited; b) EN 320-9; c) EN 400-1; d) EN 500-1; e) hard chromium.

Energy dispersive scanning analysis was performed inside the wear track in order to evaluate if the counter-face reach the substrate. Once iron is only found in the substrate, the presence of this element would indicate the complete rupture of the deposit. As can be seen in Figure 10, the spectra obtained via EDS shows that only Ni-P as-deposited and hard chromium coatings reached the substrate, confirming the results that have been explained above when the wear rate was higher for these cases.

\section{Conclusions}

In fact, heat treatments performed in Ni-P coatings considerably improve the wear resistance of the deposits.
Heat treatment conditions of $320^{\circ} \mathrm{C}$ with holding time of 9 hours and $400^{\circ} \mathrm{C}$ with holding time of 1 hour showed the best results in terms of wear behaviour, probably due to microstructural transformation from amorphous to $\mathrm{Ni}_{3} \mathrm{P}$ precipitates and $\mathrm{Ni}$ crystallites and by the formation of oxide at the coating surface. If compared to hard chromium coating, Ni-P deposits showed huge improvement in terms of wear, especially those that experienced heat treatments at $320^{\circ} \mathrm{C}$ and $400^{\circ} \mathrm{C}$. Ni-P as-deposited coating showed similar behaviour to hard chromium deposit, indicating that crystalline structure formed in Ni-P coatings after heat treatment is crucial to improve their wear properties. Apparently, unlubricated conditions used for the "ball on plate" wear test were unfavorable for the hard chromium 
deposit, whereas this coating was found to have higher average surface roughness.

The wear tests showed that both abrasive and adhesive wear mechanism acts in Ni-P and hard chromium coatings when tested against alumina counter-face, even tough abrasive mechanism is more pronounced in all cases.

\section{Acknowledgements}

Special acknowledgement to Material and Metallurgical Engineering labs at UFRGS: LACOR, LACER, LAMEF, LAPOL and LAPEC. The authors are also thankful for the financial supporting provided by CNPq.

\section{References}

1. Mandich NV, Snyder DL. Electrodeposition of chromium. In: Schelesinger M, Paunovic M, eds. Modern Electroplating. Hoboken: Wiley; 2000. p. 289-360.

2. Leahey MH. Replacement of hard chrome electroplating by tungsten carbide based high velocity oxygen fueled thermal spray. [Dissertation]. Hartford: Rensselaer Polytechnic Institute; 2009.

3. Fedrizzi L, Rossi S, Cristel R, Bonora PL. Corrosion and wear behaviour of HVOF cermet coatings used to replace hard chromium. Electrochimica Acta. 2004;49(17-18):2803-2814.

4. Balamurugan GM, Duraiselvam M, Anandakrishnan V. Comparison of high temperature wear behaviour of plasma sprayed WC-Co coated and hard chromium plated AISI 304 austenitic stainless steel. Materials \& Design. 2012;35:640-646.

5. Saghi Beyragh MR, Khameneh Asl S, Norouzi S. A comparative research on corrosion behavior of a standard, crack-free and duplex hard chromium coatings. Surface and Coatings Technology. 2010;205(7):2605-2610.

6. Sarraf SH, Soltanieh M, Aghajani H. Repairing the cracks network of hard chromium electroplated layers using plasma nitriding technique. Vacuum. 2016;127:1-9.

7. He YD, Fu HF, Li XG, Gao W. Microstructure and properties of mechanical attrition enhanced electroless Ni-P plating on magnesium alloy. Scripta Materialia. 2008;58(6):504-507.

8. Yan M, Ying HG, Ma TY. Improved microhardness and wear resistance of the as-deposited electroless Ni-P coating. Surface and Coatings Technology. 2008;202(24):5909-5913.

9. Yang H, Gao Y, Qin W, Li Y. Microstructure and corrosion behavior of electroless Ni-P on sprayed Al-Ce coating of 3003 aluminum alloy. Surface and Coatings Technology. 2015;281:176-183.

10. Novák M, Vojtěch D, Vítů T. Influence of heat treatment on microstructure and adhesion of $\mathrm{Al}_{2} \mathrm{O}_{3}$ fiber-reinforced electroless Ni-P coating on Al-Si casting alloy. Materials Characterization . 2010;61(6):668-673.

11. Balaraju JN, Rajam KS. Preparation and characterization of autocatalytic low phosphorus nickel coatings containing submicron silicon nitride particles. Journal of Alloys and Compounds. 2008;459(1-2):311-319.
12. Wojewoda-Budka J, Wierzbicka-Miernik A, Litynska-Dobrzynska L, Szczerba MJ, Mordarski G, Mosiałek M, et al. Microstructure characteristics and phase transformations of the Ni-P and Ni-P-Re electroless deposited coatings after heat treatment. Electrochimica Acta. 2016;209:183-191.

13. Vitry V, Delaunois F, Dumortier C. Mechanical properties and scratch test resistance of nickel-boron coated aluminium alloy after heat treatments. Surface and Coatings Technology. 2008;202(14):3316-3324.

14. Novák M, Vojtěch D, Vítů T. Influence of heat treatment on tribological properties of electroless Ni-P and Ni-P-Al $\mathrm{Al}_{2}$ coatings on Al-Si casting alloy. Applied Surface Science. 2010;256(9):2956-2960.

15. Vojtěch D, Novák M, Zelinková M, Novák P, Michalcová A, Fabián T. Structural evolution of electroless Ni-P coating on Al-12wt.\% Si alloy during heat treatment at high temperatures. Applied Surface Science. 2009;255(6):3745-3751.

16. Nava D, Dávalos CE, Martínez-Hernández A, Manríquez F, Meas Y, Ortega-Borges R, et al. Effects of Heat Treatment on the Tribological and Corrosion Properties of Electrodeposited Ni-P Alloys. International Journal of Electrochemical Science. 2013;8:2670-2681.

17. Rabizadeh T, Allahkaram SR, Zarebidaki A. An investigation on effects of heat treatment on corrosion properties of Ni-P electroless nano-coatings. Materials \& Design. 2010;31(7):31743179 .

18. Apachitei I, Tichelaar FD, Duszczyk J, Katgerman L. The effect of heat treatment on the structure and abrasive wear resistance of autocatalytic NiP and NiP-SiC coatings. Surface and Coatings Technology. 2002;149(2-3):263-278.

19. Vitry V, Delaunois F, Dumortier C. How heat treatment can give better properties to electroless nickel-boron coatings. $\mathrm{La}$ Metallurgia Italiana. 2009;4.

20. Ma C, Wu F, Ning Y, Xia F, Liu Y. Effect of heat treatment on structures and corrosion characteristics of electroless Ni-P-SiC nanocomposite coatings. Ceramics International. 2014;40(7 Pt A):9279-9284.

21. Franco M, Sha W, Aldic G, Malinov S, Çimenoğlu H. Effect of reinforcement and heat treatment on elevated temperature sliding of electroless Ni-P/SiC composite coatings. Tribology International. 2016;97:265-271.

22. Taheri R. Evaluation of Electroless Nickel-Phosphorus (EN) Coatings. [Thesis]. Saskatoon: University of Saskatchewan; 2002.

23. Sribalaji M, Arunkumar P, Babu KS, Keshri AK. Crystallization mechanism and corrosion property of electroless nickel phosphorus coating during intermediate temperature oxidation. Applied Surface Science. 2015;355:112-120.

24. Palaniappa M, Seshadri SK. Friction and wear behavior of electroless Ni-P and Ni-W-P alloy coatings. Wear. 2008;265(5-6):735-740.

25. Apachitei I, Duszczyk J. Autocatalytic nickel coatings on aluminium with improved abrasive wear resistance. Surface and Coatings Technology. 2000;132(1):89-98. 
26. Wang L, Gao Y, Xu T, Xue Q. Corrosion resistance and lubricated sliding wear behaviour of novel Ni-P graded alloys as an alternative to hard Cr deposits. Applied Surface Science. 2006;252(20):7361-7372.

27. Menezes PL, Nosonovsky M, Ingole SP, Kailas SV, Lovell MR, eds. Tribology for Scientists and Engineers - From Basics to Advanced Concepts. New York: Springer; 2013.

28. Sahoo P, Das SK. Tribology of electroless nickel coatings - A review. Materials \& Design. 2011;32(4):1760-1775.

29. Lee CK. Corrosion and wear-corrosion resistance properties of electroless Ni-P coatings on GFRP composite in wind turbine blades. Surface and Coatings Technology. 2008;202(19):4868-4874.
30. Vitry V, Kanta AF, Delaunois F. Mechanical and wear characterization of electroless nickel-boron coatings. Surface and Coatings Technology. 2011;206(7):1879-1885.

31. Hamada AS, Sahu P, Porter DA. Indentation property and corrosion resistance of electroless nickel-phosphorus coatings deposited on austenitic high-Mn TWIP steel. Applied Surface Science. 2015;356:1-8.

32. Sadeghzadeh-Attar A, AyubiKia G, Ehteshamzadeh M. Improvement in tribological behavior of novel sol-enhanced electroless Ni-P-SiO 2 nanocomposite coatings. Surface and Coatings Technology. 2016;307(Pt A):837-848. 